Abstracta Iranica Abstracta Iranica

Revue bibliographique pour le domaine irano-aryen

Volume 32-33 | 2013

Comptes rendus des publications de 2009-2010

\title{
Paola Orsatti. Le donne e le città : note sull'origine di alcuni personaggi nel romanzo medievale persiano
}

Anna Livia Beelaert

\section{(2) OpenEdition \\ 1 Journals}

\section{Édition électronique}

URL : http://journals.openedition.org/abstractairanica/40964

DOI : 10.4000/abstractairanica.40964

ISSN : 1961-960X

Éditeur :

CNRS (UMR 7528 Mondes iraniens et indiens), Éditions de l'IFRI

\section{Édition imprimée}

Date de publication : 1 décembre 2013

ISSN : 0240-8910

Référence électronique

Anna Livia Beelaert, « Paola Orsatti. Le donne e le città : note sull'origine di alcuni personaggi nel romanzo medievale persiano », Abstracta Iranica [En ligne], Volume 32-33 | 2013, document 431, mis en ligne le 01 juillet 2016, consulté le 03 octobre 2020. URL : http://journals.openedition.org/ abstractairanica/40964; DOI : https://doi.org/10.4000/abstractairanica.40964

Ce document a été généré automatiquement le 3 octobre 2020.

Tous droits réservés 


\title{
Paola Orsatti. Le donne e le città : note sull'origine di alcuni personaggi nel romanzo medievale persiano
}

\author{
Anna Livia Beelaert
}

\section{RÉFÉRENCE}

Paola Orsatti. « Le donne e le città : note sull'origine di alcuni personaggi nel romanzo medievale persiano », in : Giuliano Lancioni, Olivier Durand, eds., Dirāsāt Aryūliyya. Studi in onore di Angelo Arioli. Roma, La Sapienza Orientale, 2007, p. 139-163.

1 L'A. analyse l'origine et l'évolution de cinq personnages féminins dans le Husraw u Širīn de Nezāmī et sept matnawis du XII jusqu'au XV ${ }^{\mathrm{e}}$ s. qui en sont des nazīras, soit en en reprenant les protagonistes, soit en utilisant le même mètre (hazaj-e mosaddas-e maḥ̂ūuff. Les cinq sont Mehīn Bānū, Šĩīn, Maryam, Šakar et Gul. Le but est de "rendre au personnage féminin son vrai rôle (mythique, symbolique, fonctionnel) et même sa réalité historique" (p.139). Parfois la ville ou la région à laquelle un personnage est rattaché donne une indication de son origine. Ainsi, le fait que Neẓāmī rattache Mehīn Bānū, la tante de Šīrīn, à la ville de Barda', ville où lui-même, dans son Šaraf-nāma, localise le personnage de Nušāba (qui est l'équivalente de Candace dans le Roman d'Alexandre du Pseudo-Callisthène), et qu'il identifie dans le même poème avec la ville antique de Harūm, où Ferdowsī déjà paraît localiser les Amazones, explique nombre de ses traits caractéristiques. En effet, Šīiñ est élevée chez elle sans autre parent, dans ce qui est en réalité une "ville de femmes". Dans d'autres cas c'est la légende de Golinduch - sainte d'origine persane qui, après sa conversion, prit le nom de Maryam, mourut en 591 en territoire byzantin, et qui aurait rencontré le roi Husraw - qui forme un personnage. D'abord Maryam (comme l'avait déjà démontré Gianroberto Scarcia dans 
son Scirin. La regina dei Magi, Milan 2003, auquel l'A. se réfère), mais aussi, e.a., Šīrīn dans le Šììn u Husraw de Hātefī (composé entre 889/1484 et 895/1490) et Gul dans le Gul u Nawrūz de Hु$^{\mathrm{v} a ̄ j u ̄ ~ K e r m a ̄ n i ̄ ~(c o m p o s e ́ ~ e n ~ 742 / 1341) . ~ D a n s ~ c e ~ d e r n i e r ~ c a s ~ l e ~ n o m ~ d u ~}$ personnage reflète son origine (bien que sur base d'une étymologie fantaisiste, comme le précise l'A.).

2 Article riche en données et idées, qui fait partie des recherches plus élaborées de l'A., et, comme elle l'annonce, sera suivi par une édition de la Hamsa auquel appartient un des textes analysés, le Mehr u Negār de Jamālī (composé en 805/1403).

\section{AUTEURS}

ANNA LIVIA BEELAERT

Université libre de Bruxelles 